nursing mothers on an average 21 days after parturition, a discovery he made use of in his study of maturation. There are no other printed records of spontaneous ovulations in addition to that coming immediately after parturition.

The following is a summary of the results, with respect to the occurrence of ovulation, of an investigation, still under way, of the ovarian cycle in mice. The study is being carried on in the same way as for rats outlined in the preceding article.

Sixty-two female mice of various coat colors were bred, allowed to have their litters when isolated from males, kept alone or with other females, and killed at intervals during a period of 91 days. Most (52) were killed during the first 56 days at intervals of about 2 days, except between 18 and 21 days, 34 and 38 , and 50 and 56 days when the interval was a day or less. The rest of the animals were taken between 70 and $74 \frac{1}{2}$, and $87 \frac{1}{2}$ and 91 days.

The sections of the ovaries and oviducts were examined for eggs in the oviduct and for the youngest corpora lutea. In determining the time of ovulation the position of the eggs in the oviduct was considered; and the presence or absence of the youngest corpora lutea was used as a check.

The examination of these mice indicated that the second ovulation occurred at from 15 to 19 days following parturition, the third at about 35 , the fifth at 69 to 72 , and the sixth at 87 to 90 . No ovulation was found at the expected fourth, perhaps because too few animals were killed at that time. But it is significant that of those animals killed at 70 to 74 , and 87 to 91 days which fall within the expected later ovulation periods, 3 and 2 animals were found to have ovulated at the sixth and seventh periods respectively; also that none of the mice killed between the ovulation periods was found to have ovulated.

It thus appears that the normal ovulation period in mice recurs at about $17 \frac{1}{2}$ to 18 days.

$$
\text { J. A. Long, }
$$$$
\text { H. P. SмIтн }
$$

Zoological Laboratory, UNIVERSITY OF CALIFORNIA

\section{AGAR AGAR FOR BACTERIOLOGICAL USE}

AGAR AGAR is used by so many, as a basis of nutrient media, that any suggestion as to how to select the most suitable grade is worthy of consideration.

Fellers ${ }^{1}$ has recently published some bacteriological studies on agar agar. The same author $^{2}$ has also prepared a paper on the composition of agar agar and given methods for purifying commercial agar. No matter how easy the method proposed for the purification of a substance is, we have to select that which we intend to purify. One of the best ways of determining the stability of an organic substance is to find out how much it will be hydrolyzed under the conditions it is to be used. Hydrolysis is, generally, increased with temperature, and thus increased acidity at high temperatures is often due to greater hydrolysis at the high temperatures. If substances show an increased acidity at high temperatures, but when cooled back to normal temperatures return to the acidity they had before the heating, the high temperatures have not materially changed their composition. Some samples of agar agar have been known to develop a large increased permanent acidity due to autoclaving. It is evident that such samples should not be used for accurate work. The increased acidity due to autoclaving and due to titration made in hot solutions can be made use of in selecting agar agar for laboratory use.

The following described test has been found to designate the superiority of some samples of agar agar over others. Samples chosen by means of this test are always those which go completely in solution when heated with carbon dioxide free distilled water. Further media made with them have a lower acidity than media made with agars not so good by the test.

\section{THE TEST}

The test depends on the increase in acidity of water solutions of the agar due to autoclaving and to titrations made near $100^{\circ} \mathrm{C}$.

1 Fellers, Soil Science, Vol. II., No. 3, p. 255.

2 Fellers, Jour. Ind. and Eng. Chem. (Article to appear soon.) 
Sevieral samples of agar each claimed to be the best that some commercial house has in stock -are secured. Powdered and shredded agar are used alike. The shreds are cut up into half-inch lengths, so that aliquots may be more representative. (An ordinary print trimmer makes a very satisfactory agar cutter.) As many 500 c.c. Erlenmeyer flasks (Jena, pyrex or non-sol glass) as there are samples to be tested are cleaned, dried and weighed to within $0.1 \mathrm{gm}$. $4.5 \mathrm{gm}$. of agar agar are put in each flask and enough carbon dioxide free distilled water added to make the contents of the flask up to $300 \mathrm{gm}$. The flasks are shaken and put in a bath containing boiling water. They are shaken at intervals to aid solution of the agar. When the agar has dissolved the flasks are removed and contents brought up to original weight with hot carbon dioxide free distilled water.

$25 \mathrm{gm}$. aliquots of the agar solutions thus prepared are weighed out in triplicate into 350 c.c. Erlenmeyer flasks (Jena, pyrex or non-sol glass) which have just been rinsed with hot carbon dioxide free distilled water. The triplicates for each sample are designated for convenience $A, B, C$-thus those from sample No. 1 would be $1 A, 1 B$ and $1 C$.

To each $A$ flask is added approximately 250 c.c. of hot carbon dioxide free distilled water. The flasks are shaken until the contents appear homogeneous. They are stoppered and set to one side until they attain room temperature.

The $B$ and $C$ flasks are tightly stoppered by cotton plugs and autoclaved for 15 minutes under 15 pounds pressure. After autoclaving about 250 c.c. hot carbon dioxide free distilled water is added to the $B$ and $C$ flasks. The $B$ flasks are restoppered and left to cool to room temperature. The $C$ flasks are set on a steam bath. When the contents of the $C$ flasks are up to $95^{\circ} \mathrm{C}$. or above, they are removed individually and titrated at once with $N / 10$ or $N / 20$ carbon dioxide free alkali. One drop of a 1 per cent. phenolpthalein solution is used as the indicator. The titration is finished when the faintest discernible, yet permanent, pink color appears. The $A$ and $B$ flasks are titrated in the same manner after they have cooled to room temperature.

CURRENT YEAR'S TEST OF AGAR AGARS

Seven samples of agar agar were secured in answer to letters to five concerns. Five samples were shredded agar, one a powdered agar and one, "Bacto Agar." Sample No. 1 in the table is the powdered agar and No. 4 is "Bacto Agar."

All samples were uniform, clean and bright, except No. 5, which was darker, dirty and ununiform.

TABLE I

Acidity of Agar Agar Solutions and Nitrogen Content of Agars Used

\begin{tabular}{c|c|c|c|c|c}
\hline No. & $\begin{array}{c}\text { Titrated } \\
\text { R. T., } \\
\text { NA. }\end{array}$ & $\begin{array}{c}\text { Titrated } \\
\text { R. T., A. }\end{array}$ & $\begin{array}{c}\text { Inerease } \\
\text { due to A. }\end{array}$ & $\begin{array}{c}\text { Titrated } \\
\text { H., A. }\end{array}$ & $\begin{array}{c}\text { Nitrogen } \\
\text { in Agar }\end{array}$ \\
\hline 1 & $.060 \%(a)$ & $.040 \%$ & $-.020 \%$ & $.100 \%$ & $.27 \%$ \\
2 & .040 & .080 & +.040 & .120 & $-(1)$ \\
3 & .040 & .060 & +.020 & .140 & .31 \\
4 & .040 & .060 & +.020 & .088 & .31 \\
5 & .052 & .080 & +.028 & .142 & .16 \\
6 & .036 & .032 & -.004 & .076 & .27 \\
7 & .044 & .052 & +.008 & .100 & .27 \\
\hline
\end{tabular}

THE TABLE SHOWS

1. That the maximum variation in acidity between samples of agar agar when titrated at room temperatures is only .024 per cent. before autoclaving, but is doubled by autoclaving.

2. Titrating the autoclaved aliquots when hot accentuates the differences between samples, the maximum variation being greater than the greatest acidity of the unautoclaved aliquots.

3. Sample No. 6 has the lowest acidity in all cases.

Sample No. 6 is the most stable because autoclaving and heating change its reaction least.

H. A. Noyes

Purdue Agricultural Experiment Station, LAFAYETTE, INDIANA

3 R. T. $=$ Room temperature.

A. = Autoclaved.

NA. $=$ Not autoclaved.

$\mathrm{H} .=95^{\circ} \mathrm{C}$. or above.

$(1)=$ No sample left for determination.

(a) $1.0 \%=$ requirement of 1 . c.c. normal acid per 100 e.c. 